\title{
O sentido da escola: Concepções de estudantes adolescentes
}

\author{
Fernanda Moreira Leite \\ Secretaria de Educação de João Pessoa - João Pessoa - PB - Brasil \\ Manuella Castelo Branco Pessoa \\ Universidade Federal da Paraíba - João Pessoa - PB - Brasil \\ Denise Pereira dos Santos \\ Secretaria de Educação de João Pessoa - João Pessoa - PB - Brasil \\ Gabriela Fernandes Rocha \\ Universidade Federal da Paraíba - João Pessoa - PB - Brasil \\ Maria de Fatima Pereira Alberto \\ Universidade Federal da Paraíba - João Pessoa - PB - Brasil
}

\section{Resumo}

Este artigo objetiva analisar o sentido da escola para adolescentes em contexto de vulnerabilidade social. Utilizou-se como instrumento o Jogo de Sentenças Incompletas, e para análise o modelo quantitativo-interpretativo de Alves. Participaram 12 adolescentes entre 13 e 15 anos, estudantes do sexto ao nono ano de uma escola da rede pública municipal de João Pessoa, PB, localizada em uma área de vulnerabilidade social. Os dados revelam que o contexto de vulnerabilidade é marcado, sobretudo, pela falta de aspectos estruturais, que impõem aos sujeitos condições precárias de vida. Quanto à escola, os adolescentes a reconhecem como lugar do conhecimento e da aprendizagem, que possibilita a perspectiva de um futuro digno por meio da qualificação, mas o sentido identificado é o de escola como um espaço privilegiado para o encontro com o outro, para o cultivo de vínculos afetivos, para a troca, para o diálogo, a cooperação e a diversão.

Palavras-chave: Escola; adolescentes; sentido.

\section{The School direction: Conceptions of adolescent students}

\begin{abstract}
This article aims to analyze the meaning of school for adolescents in the context of social vulnerability. It was used as a tool Incomplete Sentences game and for the analyze the quantitative-interpretative model by Alves. Tehe participantes were 12 adolescents between 13 and 15 , students from the sixth to the ninth year of a municipal public school of João Pessoa, PB, located in an area of social vulnerability. The data show that the vulnerability context is marked above all by the lack of structural aspects, which require the subject precarious living conditions. As for school, teens recognize it as a place of knowledge and learning, which enables the prospect of a decent future through qualifying, but the identified direction is the school as a privileged space for the encounter with the other, for cultivation affective ties, to exchange, for dialogue, cooperation and fun.
\end{abstract}

Keywords: School; adolescents; sense.

\section{El sentido de la escuela: concepciones de estudiantes adolescentes}

\section{Resumen}

Este artículo tiene por objetivo analizar el sentido de la escuela para adolescentes en contexto de vulnerabilidad social. Se utilizó como instrumento el Juego de Sentencias Incompletas, y para análisis el modelo cuantitativo-interpretativo de Alves. Participaron 12 adolescentes entre 13 y 15 años, estudiantes del sexto al noveno año de una escuela de la red pública municipal de João Pessoa, PB, localizada en un área de vulnerabilidad social. Los datos revelan que el contexto de vulnerabilidad es marcado, sobre todo, por la falta de aspectos estructurales, que imponen a los sujetos condiciones precarias de vida. Cuanto a la escuela, los adolescentes la reconocen como lugar del conocimiento y del aprendizaje, que posibilita la perspectiva de un futuro digno por intermedio de la cualificación, pero el sentido identificado es el de escuela como un espacio privilegiado para el encuentro con el otro, para el cultivo de vínculos afectivos, para el intercambio, para el diálogo, la cooperación y la diversión. Palabras clave: escuela; adolescentes; sentido. 


\section{Introdução}

O presente artigo tem como objetivo analisar o sentido atribuído à escola por adolescentes que vivem em contexto de vulnerabilidade. Entende-se que ouvir esses adolescentes e o sentido que eles atribuem à escola em uma perspectiva contextualizada com suas condições concretas de vida pode ser um caminho para compreender a relação estabelecida com essa instituição e os vários desafios vivenciados.

As mudanças ocorridas na sociedade nas últimas décadas levaram à ampliação quantitativa do acesso à escola a fim de formar mão de obra qualificada para o capital (Schwartzman \& Castro, 2013) sem, no entanto, preocupar-se com a qualidade desse acesso (Arruda, 2011). Aliado aos processos de democratização, fruto da luta por direitos empreendida pelos trabalhadores, a ampliação do acesso à escola produziu a massificação da educação e expansão da escolarização para os pobres (Peregrino, 2011), e uma das consequências desse processo foi a inserção na escola de pessoas com perfis diferentes dos estudantes ideais por ela concebidos. A instituição e os profissionais são confrontados com um novo perfil de estudantes e muitas vezes não conseguem dialogar com eles porque as práticas escolares são organizadas em torno da "ideia de um aluno ideal, motivado para a árdua tarefa de estudar... que sabe lidar adequadamente com regras e normas escolares" (Leão, 2011, p. 104). Essa nova realidade se apresenta, então, como desafio aos profissionais, cuja formação não Ihes deu suporte para desconstruir a citada ideia de aluno "ideal" e construir práticas para lidar com o perfil real que têm diante de si nas instituições.

Proporcionar o diálogo entre as experiências dos estudantes e os saberes escolares é outro desafio (Reis, 2012). Muitos dos problemas enfrentados pelos educadores se devem à dificuldade em compreender o contexto fora da escola, o histórico, os modos de vida construídos pelos estudantes (Dayrell \& Carrano, 2014). Por isso, faz-se necessário ouvir os estudantes adolescentes a partir de sua condição social e buscar identificar que lugar a escola ocupa na vida deles e o que explica o modo como se comportam na instituição (Leão, 2011).

Outro desafio enfrentado pela escola é o de lidar com a adolescência. Fonseca e Ozella (2010) criticam a visão predominante sobre a adolescência que tende a naturalizar, padronizar e patologizar esse período da vida, enfatizando crises e conflitos universais, desconsiderando as condições concretas de vida dos sujeitos. Propõem que essa fase seja compreendida como um momento significado e interpretado social e historicamente, cujos sujeitos revelam através de suas ações o meio social onde estão inseridos, e é essa a compreensão de adolescência adotada nesse estudo (Fonseca \& Ozella, 2010). Segundo Vygotski (2006), a principal atividade da adolescência é a comunicação íntima pessoal entre os pares. $\mathrm{O}$ adolescente se torna crítico em face das exigências que lhe são impostas pelo meio em que vive, e isso reverbera em sua maneira de agir, buscando na relação com o grupo um posicionamento pessoal diante das questões que a realidade impõe à sua vida pessoal e social.

Nessa perspectiva, faz-se importante considerar as condições objetivas de vida de sujeitos adolescentes, definidos com base no Estatuto da Criança e do Adolescente (Lei no 8.069, 1990) como aqueles com idades entre 12 e 18 anos, que vivem em contextos de vulnerabilidade. Para fins deste trabalho, entende-se por vulnerabilidade a integração de três dimensões interdependentes: a dimensão individual (situações do modo de vida de cada sujeito, relacionadas às suas condições objetivas de vida, que podem contribuir para a ocorrência de agravos); a dimensão social (aspectos culturais, materiais, políticos e morais que expõem os sujeitos a condições desiguais e injustas) e a dimensão programática (ou institucional) (contribuição das instituições sociais na produção de vulnerabilidade) (Ayres, Calazans, Saletti, \& França, 2006; Meyer, Mello, Valadão, \& Ayres, 2006). Portanto, ao se falar em vulnerabilidade, levam-se em consideração fatores inerentes à organização social capitalista, engendrada na luta de classes e na exploração dos trabalhadores pelo capital, que provoca desigualdades e exclusão, sendo uma das suas formas de expressão a negação ou precário acesso aos bens materiais e culturais construídos por uma determinada sociedade.

Dos Santos, Nascimento e Menezes (2012) e Reis (2012) ressaltam que em áreas urbanas vulneráveis o acesso limitado ao lazer, esporte e cultura e o baixo nível de escolaridade restringe o potencial dos sujeitos, sendo o espaço da escola uma oportunidade de acesso a esses bens. Em pesquisas sobre o sentido da escola, Dayrell e Jesus (2013), Dos Santos e cols. (2012), Marques e Castanho (2011), Mendonça (2011) e Reis (2012) verificaram que os estudantes a reconhecem como responsável por transmitir conhecimentos e como esperança de um futuro melhor decorrente da qualificação, considerando-a uma instituição importante em suas vidas. Porém, destacam que o interesse pessoal está mais ligado à sociabilidade que ela possibilita, do que à instrução formal. A escola é considerada importante pelos adolescentes, porém, é utilizada, sobretudo, como meio para organizar as interações sociais com os pares (Facci, 2004).

Dayrell e Jesus (2013) falam de uma espécie de dilema que estudantes adolescentes vivenciam: por um lado, a negação da escola no presente, por não encontrarem motivação para a experiência escolar que lhes é oferecida; por outro lado, a consciência da centralidade da escola para seu futuro. De acordo com Mendonça (2011), esse fato revela que os estudantes aprendem o significado social da instituição, mas não o veem presente diretamente em suas vidas e, por isso, atribuem-Ihe um sentido próprio, baseado em suas realidades pessoais.

Existe também um discurso de responsabilização pessoal de estudantes pelo sucesso ou fracasso nos estudos, em detrimento das condições de ensino-aprendizagem oferecidas pela instituição (Reis, 2012). A esse respeito, Frigotto (2011) afirma que se trata de uma ideologia, na qual o problema é atribuído como responsabilidade de cada pessoa e não 
da estrutura social e das relações de poder. Essa ideologia, por sua vez, torna-se mais eficaz à medida que é interiorizada e subjetivada por cada sujeito, no caso em questão, adolescentes, situados em uma realidade concreta a partir da qual constroem significados e sentidos para a escola.

\section{Sentido}

Vigotski parte do princípio de que os seres humanos situam-se historicamente, por meio da linguagem, a partir da qual se vivencia a experiência dos significados e sentidos. Além disso, o processo de humanização ocorre no âmbito social, a partir da cultura e, portanto, o desenvolvimento, os significados e os sentidos são constituídos e transformados no curso da evolução do homem, tendo a linguagem um lugar central nesse processo, ao permitir a apropriação da cultura através da interação com o outro, com o ambiente e com a história (Costas \& Ferreira, 2011).

Para Vygotsky (2001), a linguagem também propicia o desenvolvimento, pois é através dela que, desde tenra idade, o sujeito organiza seu pensamento pela fala. Inicialmente, a linguagem é caracterizada como externa e seu uso possibilita a comunicação com outros. No decorrer do desenvolvimento, com o incremento das funções psicológicas superiores, a linguagem passa a ser internalizada e seu uso decorre não apenas para fins de comunicação, mas apresenta uma função intelectual (Costas \& Ferreira, 2011; Vygotsky, 2001). Nesse contexto, Vigotski (1934/2009) destaca que o significado como um componente indispensável da palavra é o aspecto interior desta; logo, é considerado um fenômeno da linguagem.

Do ponto de vista psicológico, o significado emerge como uma generalização, um conceito, sendo o significado da palavra um fenômeno também do pensamento (Vigotski, 1934/2009). Vigotski (1934/2009) enfatiza que os significados das palavras se desenvolvem e, portanto, modificam-se. Sendo socialmente construídos, os significados são modificados pela ação dos indivíduos e resultam na construção de uma explicação própria, processo no qual cada indivíduo relaciona os significados existentes com suas experiências anteriores e com as particularidades de sua vivência (Santos, 2010).

Esse caráter pessoal dado aos significados constitui o sentido. Sua composição envolve tanto os processos cognitivos, quanto os afetivos. Envolve aspectos cognitivos porque tem origem a partir do significado e com ele se materializa, objetiva-se; engloba também aspectos afetivos, pois, ao ser reorganizada com um sentido próprio para cada sujeito, a palavra é perpassada pela história pessoal, suas vivências e emoções. Sendo assim, o sentido não é uma síntese do significado, mas é por meio dele que se torna social (Santos, 2010).

Para Vygotsky (2001), o sentido de uma palavra é a soma de todos os eventos psicológicos que ela gera na consciência. Sendo assim, caracteriza-se como um complexo fluido e dinâmico, que emerge das palavras a partir do con- texto em que surgem (Vygotsky, 2001, Vigotski, 1934/2009). Portanto, Vigotski (1934/2009) caracteriza o sentido como algo inesgotável e que se baseia na compreensão de mundo e no conjunto da estrutura interior do indivíduo.-

Sendo objetivo deste estudo analisar o sentido da escola para adolescentes em situação de vulnerabilidade, entende-se que a Psicologia Histórico-Cultural pode contribuir para a compreensão dos sentidos aqui trazidos pelos adolescentes participantes ao colocar em primeiro plano as condições concretas, culturais e sociais de inserção dos sujeitos e a construção de significados a partir delas, dando ênfase ao papel da apropriação pessoal desses significados.

\section{Método}

\section{Lócus da Pesquisa}

A pesquisa foi realizada com estudantes adolescentes do Ensino Fundamental II ( $6^{\circ}$ ao $9^{\circ}$ ano) de uma escola da rede pública municipal de ensino da cidade de João Pessoa, localizada em um território cujo Índice de Desenvolvimento Humano (IDH) é de -0,67 (Sposati \& cols., 2010), o que significa que é uma das áreas deste município com maiores níveis de vulnerabilidade social.

\section{Participantes e amostra}

Participaram desta pesquisa 12 estudantes adolescentes, de ambos os sexos, na faixa etária de 13 a 15 anos de idade: utilizou-se a partir dos 13 anos por entender-se que a definição do ECA é um dos significados utilizados para interpretar social e historicamente a adolescência e que é adotado pela escola; e até 15 anos por ser a idade esperada para o estudante concluir regularmente o Ensino Fundamental. Foi também critério para seleção dos participantes ter histórico de reprovação e de repreensões por parte da direção da escola e da equipe técnica, por considerarmos que tais fatores indicam dificuldades na relação dos estudantes com a escola e vice-versa, podendo constituir-se em vulnerabilidade. A amostra foi definida pelo Critério de Saturação (Minayo, 2006), segundo o qual, a partir da reincidência das informações, entende-se que o conhecimento adquirido é suficiente para compreender a lógica interna do grupo estudado.

\section{Instrumentos}

A fim de selecionar os estudantes que atendiam aos critérios deste estudo, foi utilizado o instrumento denominado mosquito, um pequeno questionário no qual se perguntava nome, idade, série, se já foi reprovado, se já foi reprovado mais de uma vez na mesma série e se já foi repreendido pela direção e/ou equipe técnica da escola. 
Os demais dados trabalhados neste artigo foram coletados por meio do Jogo de Sentenças Incompletas, instrumento inicialmente desenvolvido por Raffaelli e cols. (2001) e adaptado por Alves (1998). No procedimento de aplicação, o participante é instruído a completar frases inacabadas (por exemplo: "a escola serve para...") com o primeiro conteúdo que lhe vier à mente (Raffaelli \& cols. 2001). Este instrumento foi escolhido porque permite a coleta de informações qualitativas, superando dificuldades que pudessem surgir em decorrência de um vocabulário limitado e dificuldades de atenção. Através dele buscou-se caracterizar o sentido da escola para os adolescentes através de sentenças que se referem à caracterização do contexto de vulnerabilidade, a percepção dos adolescentes com relação à escola, como a escola lida com os adolescentes e as expectativas deles com relação à escola.

\section{Procedimentos}

Foram cumpridos todos os procedimentos éticos pertinentes à pesquisa com humanos, conforme a Resolução $196 / 96$, visto que a coleta de dados foi realizada no ano de 2011. Inicialmente foi feito contato com a Secretaria de Educação e Cultura do Município de João Pessoa (SEDEC) para a realização da pesquisa em escola da rede pública municipal e, posteriormente, entrou-se em contato com a escola, deu-se prosseguimento à aplicação do questionário mosquito em turmas de $6^{\circ}$ ao $9^{\circ}$ ano e, após a seleção daqueles que estavam aptos a participar, solicitou-se autorização dos responsáveis mediante assinatura do Termo de Consentimento Livre e Esclarecido. Em seguida, iniciou-se a aplicação do Jogo de Sentenças Incompletas, em um local reservado, dentro da própria escola e acordado previamente junto à direção. O processo de aplicação do Jogo de Sentenças Incompletas foi gravado em áudio, mediante autorização dos participantes. Após isso, os dados foram transcritos para análise.

\section{Análise dos dados}

O questionário mosquito foi analisado por meio da descrição dos dados e o Jogo de Sentenças Incompletas através do modelo quantitativo-interpretativo descrito por Alves (1998, 2002), o qual se constitui de dois momentos: Investigação, classificando-se as respostas às sentenças segundo a proximidade de sentido e fazendo um agrupamento inicial dos dados; e categorização, criando-se agrupamentos válidos dos dados, segundo os critérios de exaustividade (análise de todas as formas de respostas obtidas), exclusividade (cada categoria classifica um grupo de respostas) e manutenção (as categorias devem ter um mesmo nível de inferência e interpretação das respostas, evitando-se grandes oscilações no contínuo objetividade-subjetividade).

\section{Resultados}

A fim de responder mais claramente aos objetivos deste estudo, os resultados foram dispostos em quatro tópicos: Caracterização do contexto de vulnerabilidade, a percepção dos adolescentes com relação à escola, como a escola lida com os adolescentes e as expectativas deles com relação à escola.

\section{Caracterização dos participantes e do contexto de vulnerabilidade}

Os 12 participantes deste estudo situam-se na faixa etária de 13 a 15 anos de idade, e todos afirmaram já ter sido reprovados e sofrido repreensão por parte da direção da escola ou da equipe técnica. Quanto à percepção a respeito da raça ${ }^{1}$ a que pertencem, quatro se autodenominaram como negros, dois se consideraram mulatos, três se disseram pardos, um branco, um moreno e um não respondeu.

No que se refere ao contexto de vulnerabilidade, as falas dos participantes revelaram que, no território onde eles residem o acesso a equipamentos sociais de saúde, lazer, cultura e esporte é precário, quando não inexistente, e faltam elementos como infraestrutura adequada e segurança pública para a garantia do bem-estar da população. Quando têm algum problema de saúde, por exemplo, geralmente necessitam deslocar-se para outros bairros em busca de atendimento médico.

Quanto ao acesso às possibilidades de lazer, os dados mostram que está relacionado às condições financeiras da família: quando têm possibilidade, buscam em outros bairros (shopping, praia etc.); aqueles que não têm essa opção buscam suprir essa necessidade no próprio bairro em lugares como a igreja, a escola e a casa de parentes e amigos, como afirma P5, 15 anos: "Escola e igreja. Me divirto muito na igreja ... tem um grupo de jovens, tem uma banda, aquela coisa". De um modo geral, os adolescentes revelam a precariedade desse acesso, como ilustram as seguintes falas: "Não tem nada pra eu gostar, é isso que é o problema. Se eu disser aqui você vai gostar do que? Das casas? Não tem nada pra gostar, nada, nada, nada". E ainda: "Além de lama, poça de lama, escola, ... Tem ruas, é o que eu posso falar que esse bairro tem. Mais nada" (P5, 15 anos, sexo feminino). A violência existente na área também é identificada, como se verifica nas seguintes falas: "Violento demais é, pronto, eu moro no C., eu num posso entrá aí nesse oto conjunto aí. Os dali num deixa. E nem os daqui pode ir pra lá. É tipo uma guerra" (P12, 15 anos, sexo masculino). "Vio-

\footnotetext{
1 Ainda que se compreenda a diferença entre os termos raça e etnia, na qual o termo raça se refere aos aspectos da cor de pele, e etnia a aspectos ligados à identidade, sentimento de pertença e territorialidade de um povo, e que se reconheça a pertinência dessa discussão sobretudo no contexto da América Latina (Popolo, López, \& Acuña, 2009), optamos por manter o termo raça por ser uma tendência nas pesquisas brasileiras ao referir-se ao aspecto fenotípico, ou seja, à cor da pele.
} 
lência ... as pessoas ficam matando umas as outras" (P9, 13 anos, sexo feminino).

\section{A percepção dos adolescentes com relação à escola}

Todos os participantes citaram aspectos que caracterizam a escola como um lugar que serve para estudar e aprender. No entanto, relacionaram outros pontos além do estudo como importantes neste espaço, tais como encontrar amigos e fazer amizades. Isso se revela também nos ambientes da escola citados como preferidos, pois são aqueles que possibilitam o encontro, as conversas, as brincadeiras e as atividades recreativas, como a quadra. Por outro lado, verifica-se que a sala de aula nem sempre é o local preferido e mais prazeroso porque nela os estudantes devem permanecer em silêncio, sem voz e vez, exceto nas aulas de disciplinas cujos professores estabelecem um bom relacionamento com eles. A fala de P4, 15 anos, sexo masculino, ilustra esse fato:

Oxe, tem aula chata demais, quando a aula é boa é... quando o professor é bom né, fica brincando, é bom. Mas quando é tudo chato lá eu num gosto não... Aí fica conversando com a pessoa né [o professor que é 'bom'] solta uma gracinha de vez em quando. Aí explica e o caba entende, que tem professor hoje em dia que não sabe ensinar, joga lá o livro lá, abre a página e o caba tem que fazê, né, sozim.

O espaço da escola também é visto por alguns participantes como um lugar onde se sentem protegidos contra a violência vivenciada no bairro, como se verifica na seguinte fala: "Aqui num tem nada, num é como lá no bairro, aí eu fico bem à vontade aqui. Num fico com medo" (P12, 15 anos, sexo masculino).

Sobre as disciplinas estudadas e os professores que as ministram, matemática foi considerada a mais difícil, devido ao conteúdo ser de difícil compreensão, e as disciplinas consideradas mais fáceis (história, ciências, artes, português e educação física) foram justificadas por terem um conteúdo interessante, de fácil compreensão e que conseguem relacionar com suas vivências, aliados à existência de professores que conduzem as aulas de forma prazerosa. Quanto aos professores, os considerados bons são aqueles que realizam atividades diferentes e motivadoras, explicam bem os assuntos e estabelecem um bom relacionamento com os estudantes, possibilitando o diálogo, momentos de descontração e diversão em sala de aula, instigando a vontade de aprender. Isso pode ser ilustrado com a seguinte fala:

Faz... com que eu queira gostar. Faz com que, assim, eu tenha mais vontade de fazê... ela chama atenção, do jeito que ela fala, explica, assim, ela interage com a gente, é como se fosse um teatro a aula dela. Interessante. O trabalho que ela faz com a gente é bom (P5, 15 anos, sexo feminino).
Por outro lado, justificam não gostarem de alguns professores pela impossibilidade de participação ativa nas aulas destes e, sobretudo, pelo fato de tais professores gerarem conflitos com os estudantes (brigar, reclamar, gritar), o que impossibilita um bom relacionamento.

\section{Como a escola lida com os adolescentes}

Sobre o tratamento recebido por parte da escola, um dos participantes revelou sentir-se tratado como um bebê, ou seja, de maneira infantil, ingênua, incompatível com sua idade. Dois adolescentes revelaram sentir-se tratados como filhos, pois recebem conselhos, ajuda, são bem tratados. Uma das adolescentes revelou sentir-se tratada como uma qualquer, por não poder questionar as regras existentes e outro ainda revelou sentir-se tratado como bandido, devido a situações de desrespeito por parte da escola (humilhações e preconceito com o bairro onde mora), como se verifica na fala deste participante: "Fica desrespeitano a pessoa, se humilhano, de vez em quando trata a pessoa como bandido. Eu num gosto não. [Pesquisadora: Em que momentos você percebe isso?] Quando fica falano do bairro da gente ... pros professor" (P12, 15 anos, sexo masculino). Os demais afirmaram sentir-se tratados como uma pessoa normal e como um estudante.

Sobre como gostariam de ser tratados, algumas respostas revelam o desejo de ser tratados como cidadãos de bem, com respeito e sem preconceitos com relação ao bairro onde moram, bem como o desejo de ser tratados como gente, com mais carinho e dignidade. A fala de P6, 15 anos, sexo masculino, ilustra essas categorias:

\footnotetext{
Num tivesse... Num ligasse por que, pro bairro que a pessoa mora. Uma professora mermo na sala diz quem tem o cabelo igual o meu, coisado, como fosse moicano, diz que era, pra ela era maconheiro, num sei o quê, falô com ignorância ... eu num sô nenhum maconheiro, eu só vô da escola pra casa, de casa pra banda ... eles num tão, eles moram noutros bairros, eles num conhecem o bairro da pessoa ...
}

Ao serem questionados sobre o que fazem quando se chateiam com algo na escola, a maioria dos participantes declarou não reagir, "ficar calado", "respirar fundo", "se segurar", a fim de não sofrer retaliações por parte da escola, mesmo experimentando sentimentos de raiva, aborrecimento e vontade de brigar, tendo apenas uma pessoa declarado reagir de alguma forma, afirmando que busca se vingar quando algo Ihe causa chateação. A fala de P5, 15 anos, sexo feminino, exemplifica tal questão:

\footnotetext{
Respiro fundo, mais nada. Eu penso que se eu for fazer alguma coisa assim, mais séria, pode me prejudicar, eu posso perder pontos, eu posso perder nota, eu posso ser suspensa, essas coisa, e nesse momento eu num to em condição de pelo menos perder nem que seja um ponto. Então eu tenho que pensar nisso também, eu penso no final do ano. Não me reprovar. Aí eu prefiro respirar ...
} 


\section{As expectativas dos adolescentes com relação à escola}

No que se refere às expectativas dos estudantes, verifica-se como desejo para o futuro ter um bom emprego, uma profissão, e conquistas diversas na vida pessoal, tendo a maioria declarado que para conseguir realizar tais desejos precisa estudar. A seguinte fala ilustra esse aspecto:

Porque eu tenho que aprender. Porque é necessário ... se eu não estudar, daqui pra frente eu num vou ser gente. Como diz minha avó: "tem que estudá pra ser gente". Tipo assim, no futuro, eu posso arranjar um emprego melhor, posso me formá em alguma coisa, trabalhar e ter meu dinheiro, comprar minha casa, meu carro, e assim vai (P10, 15 anos, sexo feminino).

Ao analisarem seus próprios desejos para o futuro, apontam que a escola pode auxiliá-los a alcançar tais objetivos proporcionando uma educação de qualidade, oferecendo cursos complementares que tenham relação concreta com suas aspirações e oferecendo auxílio de ordem afetiva (orientações, compreensão).

\section{Discussão}

A caracterização dos participantes, sobretudo o índice de reprovação na mesma série, permite verificar que o acesso à escola não garante a qualidade da educação, como ressaltado por Arruda (2011) e Peregrino (2011). Para Frigotto (2011), os jovens pertencentes à classe trabalhadora, que têm na escola pública sua única possibilidade de acesso ao ensino, são penalizados pelo dualismo que diferencia o tipo de escola oferecida, conforme a classe social a que pertencem.

No tocante ao aspecto da raça a que pertencem, a predominância é de adolescentes que se caracterizam como afrodescendentes (negros, mulatos, pardos e morenos), tendo apenas um se declarado branco. Este dado está em consonância com o que Frigotto (2011) discute, ao se reportar ao legado da escravatura e encontrar aí a raiz da grande maioria de negros nas camadas mais pobres da população e, portanto, na escola pública.

Quanto à vulnerabilidade do contexto onde vivem, os aspectos identificados nas falas remetem à perspectiva adotada neste estudo (Ayres \& cols., 2006; Meyer \& cols., 2006), a qual identifica na organização da sociedade os fatores que tornam os indivíduos mais vulneráveis, sobretudo no que se refere à exposição dos sujeitos a possibilidades desiguais e injustas. Dentre esses fatores, destaca-se o acesso à informação, aos meios de comunicação e a equipamentos sociais, bem como à qualidade desse acesso.

Os relatos dos adolescentes levam ainda à constatação de que as pessoas, em si, não são vulneráveis nem são responsáveis pela vulnerabilidade, mas estão vulneráveis naquele local devido à falta de estrutura adequada, ou seja, pela falta de intervenção do Estado na garantia plena de seus direitos. Portanto, as condições impostas pelo contexto social onde estão inseridas as colocam em condição de vulnerabilidade, como afirmam Meyer e cols. (2006) e Facci (2004), e a partir dessa condição vão atribuir significado e sentido às situações vivenciadas e espaços ocupados no cotidiano.

Percebem-se nas falas dos participantes evidências de significados e sentidos da escola para eles. Quanto ao significado, este é identificado nas respostas em que os adolescentes se reportam à escola como uma instituição importante, capaz de contribuir com sua formação e possibilitar, por meio do estudo, ascensão social futura por meio de empregos dignos e qualificados. Tal dado corrobora Vygotski (2006), no momento em que se assume a escola como ferramenta de mediação nas diversas esferas de conhecimento. Demonstra também que os estudantes se apropriam da exigência da economia brasileira por mão de obra qualificada, sendo a escola o lugar capaz de possibilitar tal qualificação e, futuramente, mais qualidade de vida (Schwartzman \& Castro, 2013). Pesquisas de autores como Dayrell e Jesus (2013), Dos Santos e cols. (2012), Marques e Castanho (2011), Mendonça (2011) e Reis (2012) evidenciam dados semelhantes, pois os estudantes percebem a escola como importante e fundamental para a realização de seus desejos para o futuro, tendo o estudo como a possibilidade de superar as condições de pobreza atuais.

Contudo, os dados desta pesquisa revelam também que os estudantes identificam as falhas da escola na garantia do direito a uma educação de qualidade. Esse aspecto pode ser constatado em falas que indicam: a dinâmica de algumas aulas como insatisfatória, a postura inadequada de alguns profissionais, a falta de oportunidades para expressar-se e participar dos processos decisórios, disciplinas cujos conteúdos não conseguem relacionar com suas realidades. Eles indicam ainda que há professores que não estabelecem uma relação agradável com os estudantes e, por vezes, os desrespeitam. O desrespeito fica claro quando os estudantes falam sobre como gostariam que a escola os tratasse, ao que a maioria manifesta o desejo de ser tratado com respeito e dignidade, como verificado nas categorias cidadão de bem e gente.

Dados semelhantes são discutidos por Dayrell e Jesus (2013), quanto às críticas dos estudantes a alguns professores, à relação estabelecida, ao desrespeito que sofrem, à estrutura das aulas e metodologias. Contudo, para além desses aspectos pontuais, esses autores conduzem a uma reflexão oportuna: ao se relacionar com o estudante, o professor expressa a realidade da instituição e do sistema de ensino. Portanto, algumas críticas dos estudantes adolescentes aos professores se estendem à estrutura, ao currículo e a uma cultura escolar defasada.

Analisando através da teoria de Vygotsk (2001; Vigotski, 1934/2009), essas respostas relacionadas à importância do estudo revelam a internalização, por eles, do significado construído e generalizado pela sociedade a respeito da função da escola, convencionalmente estabelecida como 
uma instituição que representa a possibilidade de um bom futuro pela qualificação. Contudo, as falas dos estudantes indicam que, para eles, o bom relacionamento estabelecido com os outros, as amizades, os momentos de descontração e diversão e os espaços da escola que propiciam essas situações são aspectos marcantes e de maior importância. Considera-se que esses aspectos indicam os sentidos construídos pelos adolescentes. Tais achados corroboram mais uma vez com a teoria vigotskiana sobre o desenvolvimento na adolescência, ficando evidente o lugar da comunicação social entre pares, sendo o espaço da escola utilizado como meio para organizar tais interações sociais (Facci, 2004) e sendo atribuído à escola tal sentido.

Outros aspectos foram ainda identificados nas falas dos estudantes deste estudo. O espaço da sala de aula foi reportado como o local de que menos gostam quando estão tendo aulas de disciplinas que não Ihes agradam e/ou de professores que não estabelecem um bom relacionamento com eles. Porém, a sala de aula se torna um lugar do qual gostam se estão tendo aulas de disciplinas que lhes agradam e com professores com quem se dão bem.

Em contrapartida, os adolescentes se referem aos amigos e ao espaço da quadra como aquilo de que mais gostam na escola, remetendo também ao que identificamos como sentido: um local que propicia o divertimento, o encontro com os amigos e a brincadeira. Esse fato pode indicar que, não tendo acesso a equipamentos e outros meios de lazer e cultura, por exemplo, os participantes deste estudo reportam à escola a possibilidade de divertir-se e cultivar os relacionamentos. A escola se torna para eles, então, mais do que um lugar para aprender; é o lugar do encontro, o lugar onde se sentem seguros e de posse de algumas possibilidades que Ihes são negadas fora dali. Tais aspectos remetem à percepção de vulnerabilidade trabalhada aqui (Ayres \& cols., 2006; Meyer \& cols., 2006), a qual considera as implicações do contexto social como produtoras de vulnerabilidade, tendo sido encontradas também em estudos de autores como Dos Santos e cols. (2012) e Reis (2012).

Esses fatores podem ser compreendidos de acordo com o que Vigotski $(2001,1934 / 2009)$ destaca sobre o sentido. Para ele, o sentido é fluido, dinâmico, emergindo a partir do contexto vivenciado. Portanto, se o contexto mudar, o sentido também muda. É o que se verifica nos relatos dos participantes, uma vez que o mesmo local (a sala de aula, por exemplo) assume sentidos diferentes, a depender do contexto que é vivenciado naquele espaço, bem como a percepção que se tem de disciplinas, conteúdos e profissionais.

Quanto à maneira de agir da escola para com eles, as respostas revelam que a maioria acredita ser levada a desempenhar os papéis que se esperam de um estudante, tais como aprender, fazer atividades e respeitar. Este aspecto mais uma vez evidencia que os estudantes adotam para si a responsabilidade de se esforçar para desempenhar tais papéis sem, no entanto, ter o direito de se expressar e contestar aquilo com que não concordam (Reis, 2012). Isso reforça a crença na responsabilidade individual e esforço pessoal para superar as dificuldades e melhorar as condições de vida, a despeito da organização social e das relações de poder (Frigotto, 2011). Há, pois, um deslocamento do eixo coletivo para a responsabilização do indivíduo (Frigotto, 2011; Reis, 2012).

Há ainda aqueles estudantes que se sentem tratados como filhos, tendo em vista que recebem conselhos e ajudas, evidenciando que os direitos de cidadania, tais como o acesso à escola, são muitas vezes concebidos como uma espécie de favores destinados àquelas pessoas que não têm como pagar por esse acesso. É importante destacar também o adolescente que diz sentir-se tratado como bandido, refletindo sua indignação frente às situações de preconceito e desrespeito a que a escola o expõe. Isso remete à concepção de adolescência hegemônica, que dá a essa fase da vida um caráter patológico, devendo ser acompanhada e podada, não atentando às incoerências sociais e desigualdades na transição da infância para a vida adulta nas diversas camadas sociais (Fonseca \& Ozella, 2010).

O panorama visto aqui leva a refletir sobre os desafios enfrentados nas instituições escolares. Neste texto, foram sinalizados alguns desses desafios, a saber: a fragilidade na formação dos profissionais para lidar com o perfil de estudantes e a realidade atual da escola; a dificuldade em estabelecer um diálogo entre o que a escola oferece e a realidade concreta dos estudantes e a dificuldade em lidar com os estudantes adolescentes. Como afirmam Dayrell e Carrano (2014), não é interessante buscar "um culpado" para as problemáticas vividas na educação contemporânea, mas sim uma compreensão mais ampla do cotidiano escolar, suas práticas e relações, tendo em vista que a escola e seus atores são integrantes da sociedade e revelam problemas sociais mais amplos. Portanto, trata-se de refletir sobre as práticas e buscar formas de intervir na realidade.

Se, por um lado, não se pode culpabilizar a escola e os profissionais pelas dificuldades de relação com os estudantes adolescentes, tampouco se pode responsabilizar o estudante (Dayrell \& Jesus, 2013). Aqui, optou-se por dar voz aos estudantes adolescentes tratando-os como atores e sujeitos de direitos e por considerar a importância de se aproximar das perspectivas deles quanto aos desafios vivenciados na instituição escolar, uma vez que predomina na sociedade uma visão negativa a respeito dos estudantes que dificulta um olhar sóbrio sobre a relação deles com a escola (Leão, 2011).

Percebe-se com os dados desta pesquisa o que Leão (2011) chama de um "processo de inserção escolar frágil" ( $p$. 107), que não possibilita aos estudantes um processo de formação humana e cidadã que Ihes favoreça a inserção social e profissional. Portanto, trata-se de um sistema educacional que passou por uma grande expansão do acesso, mas que não se revela democrático de fato, uma vez que continua marcado por desigualdades (Peregrino, 2011).

\section{Considerações finais}

Os dados deste estudo permitem caracterizar a vulnerabilidade do local onde vivem os participantes e o sentido 
atribuído à escola com base em suas vivências. No que tange à vulnerabilidade, verificou-se que o contexto é carente de aspectos estruturais que garantam qualidade de vida, tais como infraestrutura adequada, acesso a equipamentos sociais e segurança pública. Portanto, trata-se de um contexto perpassado por desigualdades sociais, onde se verifica a omissão do Estado na garantia dos direitos dos cidadãos, implicando, assim, em condições de vida precárias.

As condições de vida evidenciadas, nesse contexto de vulnerabilidade, implicam diretamente na constituição do significado e do sentido que eles atribuem à escola. Eles internalizam o significado construído socialmente a respeito da escola, ou seja, de que ela é um espaço que representa a possibilidade de estudar, aprender e ascender socialmente através de um bom emprego que a escolaridade adequada Ihes pode possibilitar. Esse significado, baseando-se na compreensão de mundo e nas vivências concretas dos sujeitos, é enriquecido e ganha amplitude, carregada de motivos e necessidades: o sentido. Consideramos aqui como evidências do sentido da escola para os estudantes adolescentes o fato de ser a escola o lugar do encontro, da formação de vínculos, de cultivo dos laços afetivos, do lazer.

Diante dos dados discutidos neste artigo, reitera-se a importância de considerar os estudantes adolescentes como atores e sujeitos de direitos, cujas concepções devem ser consideradas nas tomadas de decisão e nas iniciativas que visam intervir na rotina escolar. Há uma nova geração, diferente do estudante considerado ideal. Um adolescente cujas condições objetivas de vida precisam ser consideradas no modo como se articula e interfere na escola.

Como contribuições desses dados para a discussão no campo da Psicologia Escolar e Educacional, faz-se relevante pensar sobre a atuação do psicólogo nesse contexto da relação dos estudantes adolescentes com a escola. Ressalta-se a importância de o profissional de Psicologia compreender o ser humano como constituído pela realidade histórico-social e, desse modo, criar espaços de discussão, atuando como um mediador e problematizando a realidade, na busca de enfrentar situações naturalizadas no contexto escolar que culpabilizam os atores.

Considera-se como limitação deste estudo o fato de ter abrangido apenas uma unidade escolar, tendo em vista a abordagem qualitativa e a busca por trabalhar com as falas dos estudantes adolescentes. Porém, acredita-se que os dados aqui trabalhados contribuem para a reflexão em torno do atual debate sobre a situação das escolas, as relações estabelecidas, o sistema de ensino e as metodologias; acredita-se também que possam dar margem a novos estudos, mais abrangentes e que contribuam para iniciativas políticas no âmbito educacional.

\section{Referências}

Alves, P. B. (1998). O brinquedo e as atividades cotidianas de crianças em situação de rua. Dissertação de Mestrado, Universidade Federal do Rio Grande do Sul. Recuperado:
16 ago. 2010. Disponível: http://www.lume.ufrgs.br/bitstream/ handle/10183/1890/000222267.pdf?sequence=.

Alves, P. B. (2002). Infância, tempo e as atividades cotidianas de crianças em situação de rua: as contribuições da teoria dos sistemas ecológicos. Tese de Doutorado, Universidade Federal do Rio Grande do Sul. Recuperado: 16 ago. 2010. Disponível: http:// www.lume.ufrgs.br/bitstream/handle/10183/2554/000372073. pdf?sequence $=1$.

Arruda, M. C. C. (2011). Escola pública e pobreza no Brasil: A ampliação para menos [Resenha]. Cadernos de pesquisa, 41(143), 664-666.

Ayres, J. R. C. M., Calazans, G. J., Saletti, H. C., Filho, \& França, I.,-Júnior. (2006). Risco, vulnerabilidade e práticas de prevenção e promoção da saúde. Em G. W. S. Campos, M. C. S. Minayo, M. Akerman, M. Drumond, Júnior, \& Y. M. Carvalho (Orgs.), Tratado de Saúde Coletiva (pp. 375-417). Rio de Janeiro, RJ: Hucitec, Fiocruz.

Costas, F. A. T. \& Ferreira, L. S. (2011). Sentido, significado e mediação em Vygotsky: Implicações para a constituição do processo de leitura. Revista Iberoamericana de Educación, 55, 205-223.

Dayrell, J. \& Carrano, P. (2014). Juventude e ensino médio: Quem é esse jovem que chega à escola. Em J. Dayrell, P. Carrano, \& C. L. Maia (Orgs.), Juventude e ensino médio (pp. 101- 133). Belo Horizonte, MG: Editora UFMG.

Dayrell, J. \& Jesus, R. E. (2013). A exclusão de jovens de 15 a 17 anos no ensino médio no Brasil: Desafios e perspectivas. [Relatório de Pesquisa]. Recuperado de http://observatoriodajuventude.ufmg. br/publication/view/pesquisa-unicef-a-exclusao-de-jovens-de-15a-17-anos-no-ensino-medio-no-brasil/. Acesso em 04 de abril de 2016.

Dos Santos, R. M., Nascimento, M. A., \& Menezes, J. A. (2012). Os sentidos da escola pública para jovens pobres da cidade do Recife. Revista Latinoamericana de Ciencias Sociales, Niñez y Juventud, 10(1), 289-300.

Facci, M. G. D. (2004). A periodização do desenvolvimento psicológico individual na perspectiva de Leontiev, Elkonin e Vigostski. Cadernos Cedes, 24(62), 64-81.

Fonseca, D. C. \& Ozella, S. (2010). As concepções de adolescência construídas por profissionais da estratégia de Saúde da Família. Interface - Comunicação, Saúde, Educação, 33(14), 411-424.

Frigotto, G. (2011). Juventude, trabalho e educação no Brasil: Perplexidades, desafios e perspectivas. Em R. Novaes \& P. Vannuchi (Orgs.), Juventude e sociedade: Trabalho, educação, cultura e participação (pp. 180-216). São Paulo, SP: Editora Fundação Perseu Abramo.

Leão, G. (2011). Entre sonhos e projetos de jovens, a escola... Em 
J. Dayrell, M. I. C. Moreira, \& M. Stengel (Orgs.), Juventudes contemporâneas: Um mosaico de possibilidades - IV Simpósio Internacional sobre a Juventude Brasileira (pp. 99-115). Belo Horizonte, MG: Editora PUC Minas.

Lei n. 8.069, de 13 julho de 1990 (1990, 13 de julho). Dispõe sobre o Estatuto da Criança e do Adolescente e dá outras providências. Brasil: Diário Oficial da União.

Marques, P. B., \& Castanho, M. I. S. (2011). O que é a escola a partir do sentido construído por alunos. Psicologia Escolar e Educacional, 15(1), 23-33.

Mendonça, S. G. L. (2011). A crise de sentidos e significados na escola: a contribuição do olhar sociológico. Cadernos Cedes, 31(85), 341-357.

Meyer, D. E. E., Mello, D. F., Valadão, M. M., \& Ayres, J. R. C. M. (2006). "Você aprende. A gente ensina?" Interrogando relações entre educação e saúde desde a perspectiva da vulnerabilidade. Cad. Saúde Pública, 22(6), 1335-1342.

Minayo, M. C. S. (2006). O desafio do conhecimento: Pesquisa qualitativa em saúde ( $2^{\mathrm{a}}$ ed). São Paulo, SP: HUCITEC/ ABRASCO.

Peregrino, M. (2011). Juventude e escola: Elementos para a construção de duas abordagens. Em J. Dayrell, M. I. C. Moreira, \& M. Stengel (Orgs.), Juventudes contemporâneas: Um mosaico de possibilidades - IV Simpósio Internacional sobre a Juventude Brasileira (pp. 81-98). Belo Horizonte, MG: Editora PUC Minas.

Popolo, F., López, M., \& Acuña, M. (2009). Juventude indígena e de ascendência africana na América Latina: desigualdades sóciodemográficas e desafios políticos. Organização Ibero-americana de Juventude: Madrid.
Raffaelli, M., Koller, S. H., Reppold, C. T., Kuschick, M. B., Krum, F. M., \& Bandeira, D. R. (2001). How Do Brazilian Street Youth Experience 'The Street'? Analysis Of A Sentence Completion Task. Childhood: A Global Journal of Child Research, 8(3), 396-415.

Reis, R. (2012). Experiência escolar de jovens/alunos do ensino médio: Os sentidos atribuídos à escola e aos estudos. Educação e Pesquisa, 38(03), 637-652.

Santos, L. G. (2010). Educação e o inconsciente sócio-histórico: uma análise da função da escolarização na construção de sentidos e significados do desemprego. Dissertação de Mestrado não Publicada. Universidade Federal de Mato Grosso do Sul.

Schwartzman, S. \& Castro, C. M. (2013). Ensino, formação profissional e a questão da mão de obra. Ensaio: avaliação e políticas públicas em educação, 21(80), 563-624.

Sposati, A., Ramos, F., Koga, D., Conserva, M., Silveira, J. C., \& Gambardella, A. (2010). Topografia Social da Cidade de João Pessoa. João Pessoa, PB: Editora Universitária da UFPB.

Vigotski, L. S. (2009). A construção do pensamento e da linguagem $\left(2^{\mathrm{a}}\right.$ ed). (P. Bezerra, trad.). São Paulo, SP: WMF Martins Fontes. (Original publicado em 1934).

Vygotski, L. S. (2006). Obras Escogidas. Tomo IV. Madrid: Visor.

Vygotsky, L. S. (2001). Pensamento e linguagem. [Edição eletrônica]. Recuperado: 03 mai. 2011. Disponível: http://www.ebooksbrasil. org/eLibris/vigo.html. 


\section{Sobre as autoras}

Fernanda Moreira Leite (fernandaleitem@gmail.com)

Mestre em Psicologia Social pela Universidade Federal da Paraíba, Psicóloga na Secretaria de Educação do Município de João Pessoa.

Manuella Castelo Branco Pessoa (manucastelobranco2@gmail.com)

Doutoranda em Psicologia Social - Universidade Federal da Paraíba.

Denise Pereira dos Santos (denyps@gmail.com)

Mestre em Psicologia Social pela Universidade Federal da Paraíba, Psicóloga na Secretaria de Educação do Município de João Pessoa.

Gabriela Fernandes Rocha (gabifernandesrocha@gmail.com)

Doutoranda em Psicologia - Universidade Federal da Paraíba.

Maria de Fatima Pereira Alberto (jfalberto@uol.com.br)

Doutora em Sociologia pela Universidade Federal de Pernambuco, Professora Associada do Departamento de Psicologia e do Programa de Pós-Graduação em Psicologia Social da Universidade Federal da Paraíba (UFPB). Coordenadora do Núcleo de Pesquisas e Estudos sobre o Desenvolvimento da Infância e Adolescência (NUPEDIA), integrante do GT Juventude e Resiliência da ANPEPP, bolsista produtividade do CNPq.

Trabalho derivado de dissertação de mestrado pelo Programa de Pós-Graduação em Psicologia Social da Universidade Federal da Paraíba. 